Accelerator Department BROOKHAVEN NATIONAL IAABORATORY Associated Universities, Inc. Upton, L.I., N.Y.

AGS DIVISION TECHNICAL NOTE

No. 55

P. Clarke

October 8, 1968

DESIGN OF A VACUUM SYSTEM FOR SPARE DÜOPIASMATRON ION SOURCES

\title{
1) Objective
}

To design a vacuum system to test and hold AGS spare duoplasmatron ion sources. The system should be failsafe and maintenance free.

\section{2) Principle}

The main criterion for the vacuum system is that an oxide cathode can be outgassed, activated and held for long periods as an AGs machine spare.

The major outgasing products from an oxide cathode during activation are water vapor and carbon monoxide. These gases must be pumped to a pressure less than $10^{-5}$ torr. There must be no hydrocarbon contamination from the vacuum system or pumps. Many vacuum systems can do this job but sorption pumps are ideal.

Sorption pumps when cooled to liquid nitrogen temperature can reduce the total pressure in a vacuum system to less than $10^{-2}$ torr. The particle pressure of gases like $\mathrm{H}_{2} \mathrm{O}, \mathrm{CO}, \mathrm{N}_{2}$, Ar and $\mathrm{O}_{2}$ are reduced to pressures less than $10^{-5}$ torr while gases like $\mathrm{H}_{2}$, Ne and $\mathrm{He}$ are on $1 \mathrm{y}$ reduced to pressures less than $10^{-2}$ torr. It is these latter gases with low activation energies for sorption that make the total pressure in sorption pumped vacuum systems when the starting gas is air at atmospheric pressure. 
3) Vacuum System Design and Tests

The vacuum system is shown in Fig. 1. Each sorption pump holds about two pounds of zerolite. One pump was charged with Linde molecular sieve \#13X, the other with Linde molecular sieve 非 . The molecular sieve 非13X seemed to pump the outgassing products from the filament at liquid nitrogen temperature better than molecular sieve 非A. This observation needs further testing.

The filament was outgassed slowly by carefully increasing the filament heater current until the ion source T.C. gauge indicated 200 microns. As the filament outgassed, the pressure was held at 200 microns by adjusting the filament heater current. The T.C. gauge above the sorption pump never rose above 20 microns.

The filament was considered outgassed when the filament heater current read 28 amp and the ion source T.C. gauge indicated 25 microns.

After the filament was outgassed, the valve above the sorption pump was closed and $\mathrm{H}_{2}$ leaked into the vacuum system through a heated $\mathrm{Pd}$ leak. When the pressure in the vacuum system indicated 200 microns, the Pd leak was cooled and the pressure stabilized at 200 microns. The ion source was then pulsed at 250 volts and a 25 amp arc discharge was established in the ion source.

The ion source was isolated from the sorption pump by the closed valve and so could be considered a vacuum tube with no sources or sinks of gas (almost). The only attention the system needs is to leak in $\mathrm{H}_{2}$ gas periodically beeause the $\mathrm{H}_{2}$ is ion pumped in the source.

Life test data is not available. The first filament operated normally for 36 hours before installation in the AGS linac. 
BRDOKHAVEN NATIONAL LABORATORY

DY

CHKD. BY _.....DATE
SUBJECT

SHEET ND.

JoE ND.

DEPT. QR PROJECT
QR F.

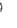

